\title{
Influence of Migration Status and Gender on Awareness of Cardiovascular Risk Factors and Cardiovascular Health in a Group of Turkish Immigrants and Indigenous Austrians
}

\author{
Teresa Wipperich ${ }^{1^{*}}$, Michael Sponder ${ }^{1}$, Lena Stütz ${ }^{1}$, Dondue Demir ${ }^{1}$, Alexandra Kaider ${ }^{2}$ and Jeanette Strametz-Juranek $^{1}$ \\ ${ }^{1}$ Department of Cardiology, Medical University of Vienna, Vienna, Austria \\ ${ }^{2}$ Center for Medical Statistics, Informatics and Intelligent Systems, Section for Clinical Biometrics, Medical University of Vienna, Vienna, Austria \\ "Corresponding author: Teresa Wipperich, Department for Cardiology, Medical University of Vienna, Waehringer Guertel 18-20, Vienna, 1090, Austria, Tel: \\ 00436508124909; E-mail: teresa.haidinger@meduniwien.ac.at
}

Received date: May 03, 2014; Accepted date: Jul 17, 2014; Published date: Jul 24, 2014

Copyright: (c) 2014 Haidinger W, et al. This is an open-access article distributed under the terms of the Creative Commons Attribution License, which permits unrestricted use, distribution, and reproduction in any medium, provided the original author and source are credited.

\begin{abstract}
Background: The aim of this study was to investigate differences in the awareness of cardiovascular risk factors, preventive action taken and barriers to cardiovascular health between the Turkish minority living in Austria and the indigenous people.
\end{abstract}

Methods: A total of 1800 anonymous questionnaires were handed out to 573 women and 336 men with no immigration background and compared with 257 female and 250 male Turkish migrants in Turkish language living in Austria.

Results: Cardiovascular disease was more likely to be identified as the leading cause of death by indigenous Austrians (75\%) than by the Turkish participants. Diabetes mellitus II (DM II) was only identified by around $27 \%$ of the Austrians and $22 \%$ of the Turkish women and $28 \%$ of the Turkish men. Albeit Austrians can identify more risk factors and have a lower actual CVD risk, their main barrier to CVD health being the inability to assess their personal risk correctly, while Turkish immigrants show a lack of knowledge of how to access preventive screening.

Conclusion: The main barrier for preventive action for the Turkish minority is a low educational and acculturation level, while Austrian women in particular have difficulties in assessing their personal risk correctly.

Keywords: Cardiovascular disease; Cardiovascular prevention; Men; Women; Migration

\section{Background}

Cardiovascular disease (CVD) is the leading cause of death for men and women in Austria, showing a slight decline in male mortality from 2003-2009 from $36.7 \%$ to $35.6 \%$ [1], and a stable mortality rate in women. The largest group immigrating to Austria are Germans, followed by Serbo-Croatians and Turks. A total amount of 1.54 million living in Austria has a migration background; 185,000 are from Turkey [2]. The Austrian healthcare system offers free access to outpatient and inpatient medical care and it is designed as a social system that aims to prevent discrimination of individuals of groups. The study "The mosque campaign" conducted by Hochleithner et al. in the year 2002 showed that although Austria provides free healthcare services, a large number of Turkish women were not aware of their CVD risk factors and $85 \%$ of the first generation stated problems of accessing the Austrian healthcare system [3]. After an educational programme for these women lack of awareness of the main CVD risk factors decreased significantly. The heart risk for women in Turkey is estimated as the highest throughout Europe and migration does not improve health [4]. According to data from the US and Great Britain, migration of women in particular leads more often to a higher prevalence and a lack of awareness of CVD risk factors [5]. These results cannot be assumed for Central Europe, as the country of origin of the immigrants and the healthcare systems differ enormously. Despite the data available for women, a substantial gap remains concerning men. Therefore the present study was not only performed to assess the influence of immigration of women but also of men on cardiovascular prevention, self-perception of CVD risk and barriers to cardiovascular health, using the example of Turkish immigrants as they are the largest group of non EU-immigrants in Austria who do not benefit from the Austrian healthcare system.

\section{Material and Methods}

\section{Study and design}

The study was approved by the local ethical committee of the Medical University of Vienna (Vienna, Austria). All participants gave informed consent. For this cross-sectional study a total of 1800 anonymous questionnaires were randomly distributed to 1100 Austrian and 700 Turkish subjects. The Austrian subjects are from three large companies in Vienna, a gynaecology practice in Salzburg, a general practitioner's surgery in Langenstein, and the Urology. Department at Elisabethinen Hospital in Linz, Upper Austria. The three companies in which the questionnaire was distributed included Vienna's largest energy provider, with 5500 employees, and two mobile phone providers with 1400 and 9700 employees respectively. Participant selection was not subject to any special criteria. The Urology Department represented an inpatient setting. Corporate 
Citation: Haidinger T, Sponder M, Stütz L, Demir D, Kaider A, et al. (2014) Influence of Migration Status and Gender on Awareness of Cardiovascular Risk Factors and Cardiovascular Health in a Group of Turkish Immigrants and Indigenous Austrians. J Gen Practice 2: 169. doi:10.4172/2329-9126.1000169

Page 2 of 8

employees composed $62 \%$ of the Austrian participants and $38 \%$ were from a gynaecology practice, the general practitioner's surgery and the Urology Department. The Turkish subjects were recruited in mosques in Vienna, especially at the Friday prayer, in cultural centres in Vienna and at a general practitioner's surgery in Vienna. Patients from the general practitioner composed $40 \%$ of the Turkish participants, $35 \%$ were recruited in cultural centres and $25 \%$ in mosques. For inclusion respondents were required to be at least 18 years of age. The Turkish participants could choose between a German or Turkish written questionnaire. $45 \%$ of the Turkish men chose the German written questionnaire compared to $21 \%$ of Turkish women. Questionnaire completion took at least 20 minutes. All participants received a short description of the objectives of the study and how to use the questionnaire. A total of 909 Austrian respondents (82.5\%; 573 women and $336 \mathrm{men}$ ) and 507 Turkish respondents (72.4\%; 257 women and 250 men) completed the survey and filled out the anonymous standardized questionnaire, which assessed CVD awareness, selfassessment of personal CVD risk, and preventive action taken. As there were large age differences between the Austrian and Turkish respondents, the answers were weighted. To prevent selection bias, survey participants were not recruited from cardiology departments or clinics.

\section{Survey methods and definitions}

Survey participants were given an anonymous questionnaire consisting of 41 questions for Austrians and 57 questions for the Turkish group for both genders and an additional 4 questions for women to assess the use of hormone therapy, contraceptive use, number of pregnancies, and gestational diabetes. The 16 additional questions for the Turkish group mainly examined the acculturation level and other social indicators. The questionnaire design was adopted from the 2006 Women's Awareness, Preventive Action, and Barriers to Cardiovascular Health study performed by Mosca et al. [6]. After the questionnaires were completed, each was coded with a number. The questionnaire was marked at the top as either "Questionnaire for female respondents" or "Questionnaire for male respondents" to differentiate between female and male respondents. It was divided into four parts. In part 1, "General Information and Gender Factors", general information was collected about the survey participants, as well as about their knowledge of CVD risk factors and the leading cause of death in Austria.

To assess the acculturation level of Turkish migrants, the 5 point Likert type scale (adapted by Sash) [7] was used. Four specific questions about the language spoken in certain situations were asked. If the participant answered that he/she speaks/thinks only in Turkish, they received one point, more Turkish than German 2 points, both languages the same 3 points, more German than Turkish 4 points and only German 5 points. These points were summed up and according to the score estimate a lower assimilation grade was reached with less than 3 points and a higher assimilation grade was achieved with more than 3 points.

Part 2, "Personal Health Behaviour", investigated participants' lifestyles, in particular, nutrition, smoking habits, alcohol consumption, and physical exercise. Respondents were also asked about their individual history of CVD such as preexisting coronary artery disease, myocardial infarction, or stroke, and their individual risk factors such as type 2 diabetes, hypertension, high cholesterol concentrations, obesity, and positive family history.
In part 3, "Preventive Action Taken and Self-Assessment of Individual CVD Risk", participants were asked closed-ended questions related to their personal preventive behaviour during the preceding year. Participants were also asked about factors that may have prompted preventive action for their children or partners.

Numerous studies support the prognostic importance of risk factors to develop a CVD. As already shown in 1997, 30\% of all coronary heart disease deaths in the US each year are related to cigarette smoking [8]. Especially obesity is associated with an increase of CVD and other comorbidities leading to CVD as Diabetes mellitus or hypertension. A 10 $\mathrm{kg}$ higher body weight is associated with a $3 \mathrm{mmHg}$ higher systolic blood pressure and an estimated 12\% increased risk for CVD [9]. Obesity, high blood pressure levels, low physical activity and the higher risk for new-onset diabetes are strongly linked. A study could show that women with a high physical activity, normal weight and healthy diet had an $88 \%$ lower risk for developing diabetes [10]. Men and women with diabetes have a two to fourfold higher risk of CVD compared with those without diabetes [11]. According to the American Heart Association there is no current justification to recommend alcohol as a cardioprotective strategy.

According to the prevention guidelines from the American Heart Association smoking cessation, physical activity, heart healthy diet, weight management and cholesterol control are regarded as Class I recommendations independently from the actual CVD risk [12].

Perceived risk was based on the respondents' self-assessment of their individual risk of heart disease (high, moderate, or low). Actual personal risk was determined using the National Cholesterol Education Programme, Adult Treatment Panel III, criteria [13]. Respondents who stated that they had had heart disease and/or a stroke or transient ischemic attack, type 2 diabetes, or stenosis of the coronary arteries were classified as at high risk. Respondents were classified as at low risk if they fulfilled all of the following conditions: were younger than 55 years; did not have diabetes, did not have high cholesterol concentrations, hypertension, depression, or migraine headaches, had no positive family history, did not smoke and had no previous known stroke or transient ischemic attack, or myocardial infarction. All other respondents were classified as at intermediate CVD risk. The advantage of this classification is that it enables direct comparison of actual and perceived CVD risk.

In part 4 barriers to cardiovascular health and a healthy heart lifestyle were assessed.

\section{Statistical analysis}

Continuous outcome variables are given as mean (SD), and categorical variables are given as frequency (percentage). The $\mathrm{X}^{2}$ test was used to test for gender differences pertaining to categorical outcome variables. The nonparametric Wilcoxon rank sum test and the two-sample t-test, respectively, were used to compare ordered categorical and continuous variables between groups of respondents. Logistic regression analysis was performed to evaluate whether the degree of awareness influences the probability of engagement in active CVD prevention. The degree of awareness was measured as the number of cardiovascular risk factors selected by the respondent. The nonparametric Spearman correlation coefficient was used to describe the correlation of the respondent's level of educational achievement with the degree of awareness.

In addition we weighted the answers given, so that Austrian and Turkish men and women can be compared directly. Statistical analyses 
Citation: Haidinger T, Sponder M, Stütz L, Demir D, Kaider A, et al. (2014) Influence of Migration Status and Gender on Awareness of Cardiovascular Risk Factors and Cardiovascular Health in a Group of Turkish Immigrants and Indigenous Austrians. J Gen Practice 2: 169. doi:10.4172/2329-9126.1000169

Page 3 of 8

were performed using SAS software (version 9.2, 2002-2008; SAS Institute, Inc., Cary, North Carolina). All P-values are the result of two-sided tests. $\mathrm{P}<0.05$ was considered statistically significant.

\section{Results}

\section{Characteristics of respondents}

The demographic characteristics of the women and men participating in the full survey are listed in Table 1 by ethnic group. Turkish women were on average six years younger than the Austrian women. The same finding was true for the male group, whereas Turkish men were on average 24 years younger compared to the male Austrians (30.9 vs. 54.1). Half of the Austrian men and women had a positive family history for CVD, compared to $33.1 \%$ of Turkish women and $19.1 \%$ of Turkish men.

\begin{tabular}{|c|c|c|c|c|}
\hline \multirow[b]{2}{*}{ Characteristics } & \multicolumn{4}{|c|}{ Respondents } \\
\hline & $\begin{array}{l}\text { Austrian } \\
\text { Women }\end{array}$ & $\begin{array}{l}\text { Turkish } \\
\text { Women }\end{array}$ & $\begin{array}{l}\text { Austrian } \\
\text { Men }\end{array}$ & Turkish Men \\
\hline \multicolumn{5}{|l|}{ Age, in years } \\
\hline Mean (SD) & $47.5(14.3)$ & $41.6(10.5)$ & $54.1(15.0)$ & $30.9(10.3)$ \\
\hline Range & $18-89$ & $18-67$ & $18-90$ & $18-62$ \\
\hline \multicolumn{5}{|l|}{ Marital Status } \\
\hline Single & $152(26.81)$ & $13(4.06)$ & $60(17.86)$ & $20(11.49)$ \\
\hline Married & $306(53.9)$ & $282(88.12)$ & $235(69.94)$ & $134(76.57)$ \\
\hline Divorced & $71(12.52)$ & $6(1.90)$ & $33(9.82)$ & $21(12.0)$ \\
\hline Widowed & $38(6.7)$ & $19(5.93)$ & $7(2.08)$ & $0(0.0)$ \\
\hline \multicolumn{5}{|l|}{ No. of children } \\
\hline 0 & $174(30.53)$ & $25(7.81)$ & $88(26.35)$ & $43(27.22)$ \\
\hline 1 & $127(22.28)$ & $20(6.25)$ & 65 (19.46) & $13(8.23)$ \\
\hline 2 & $180(31.58)$ & $50(15.62)$ & $113(33.83)$ & $53(33.54)$ \\
\hline 3 & $69(12.11)$ & $90(28.13)$ & $43(12.87)$ & $8(5.06)$ \\
\hline$>3$ & $20(3.51)$ & $135(42.19)$ & $25(7.49)$ & $41(25.95)$ \\
\hline Single Parent & $78(14.36)$ & - & $8(2.40)$ & - \\
\hline Living alone & $152(28.00)$ & $4(1.6)$ & $47(14.16)$ & $14(5.6)$ \\
\hline $\begin{array}{l}\text { Taking care of a } \\
\text { sick relative }\end{array}$ & $72(12.86)$ & $48(15.14)$ & $29(8.68)$ & $59(33.52)$ \\
\hline \multicolumn{5}{|c|}{ Educational achievement level } \\
\hline $\begin{array}{l}\text { Compulsary } \\
\text { school }\end{array}$ & $76(14.36)$ & $216(76.06)$ & $31(9.25)$ & $66(40.24)$ \\
\hline Vocational school & $160(28.32)$ & $6(2.11)$ & $147(43.88)$ & $23(14.02)$ \\
\hline Secondary school & $160(28.32)$ & $26(9.15)$ & $65(19.40)$ & $14(8.53)$ \\
\hline $\begin{array}{l}\text { 3-Year-non- } \\
\text { diploma-granting } \\
\text { school }\end{array}$ & $46(8.14)$ & $20(7.04)$ & $33(9.85)$ & $40(24.39)$ \\
\hline $\begin{array}{l}\text { University } \\
\text { graduate }\end{array}$ & $123(21.77)$ & $16(5.63)$ & $59(17.61)$ & $21(12.80)$ \\
\hline
\end{tabular}

\begin{tabular}{|l|l|l|l|l|}
\hline Employement & $229(40.32)$ & $29(9.06)$ & $174(52.10)$ & $150(86.21)$ \\
\hline Full Time & $129(22.71)$ & $22(6.88)$ & $8(2.4)$ & $4(2.30)$ \\
\hline Part Time & $44(7.75)$ & $199(62.19)$ & $4(1.4)$ & $2(1.15)$ \\
\hline Unemployed & $122(21.48)$ & $21(6.56)$ & $139(41.60)$ & $10(5.7)$ \\
\hline Retired & $44(7.75)$ & $47(4.38)$ & $9(2.69)$ & $8(4.60)$ \\
\hline Other & $125(23.45)$ & $266(89.86)$ & $10(3.11)$ & $59(39.60)$ \\
\hline Income after taxes, $€$ & $217(40.71)$ & $22(7.43)$ & $92(28.57)$ & $53(35.57)$ \\
\hline$<800$ & $163(30.58)$ & $5(1.69)$ & $173(53.73)$ & $25(16.78)$ \\
\hline $800-1500$ & $28(5.25)$ & $3(1.01)$ & $47(14.60)$ & $12(8.05)$ \\
\hline $1500-2500$ & & $23(7.17)$ & & $34(24.82)$ \\
\hline$>2500$ & & & & $103(75.18)$ \\
\hline Acculturation Level & & & & \\
\hline High Level & & & & \\
\hline Low Level & & & & \\
\hline *Data are given as number of respondents (\%) & \\
\hline
\end{tabular}

Table 1: Demographic characteristics of respondents who completed the survey.*

Although Turkish women were younger, they suffered significantly more often from hypertension ( $19 \%$ vs. $34 \%)$. Turkish men were also more affected by hypertension (37.1\%) compared to Austrian men (34.6\%). High cholesterol levels were reported by $17.3 \%$ of Austrian women compared to $32.8 \%$ of Turkish women and by $24.2 \%$ of Austrian men compared to $34.2 \%$ of Turkish men. Diabetes was reported significantly more often by the Turkish participants. $14.7 \%$ of Turkish women and $23.5 \%$ of Turkish men suffered from diabetes compared to $3.6 \%$ of Austrian women and $7.8 \%$ of Austrian men.

\section{Awareness of CVD and its risk factors}

Leading cause of death: Turkish women and men were asked about the leading cause of death for women and men separately as shown in Table 2, whereas the Austrians were asked about the leading cause of death in general in Austria (Table 3). Therefore these results cannot be compared directly.

\begin{tabular}{|l|l|l|}
\hline & \multicolumn{2}{|c|}{ Respondents } \\
\hline Cause of Death & Austrian Women & Austrian Men \\
\hline Cardiovascular disease & $409(75.32)$ & $250(75.08)$ \\
\hline Cancer & $108(19.89)$ & $73(21.92)$ \\
\hline Accidents & $8(1.47)$ & $8(2.40)$ \\
\hline Digestive tract disease & $8(1.47)$ & $2(0.60)$ \\
\hline Respiratory tract disease & $10(1.84)$ & 0 \\
\hline *Data are given as number of respondents (\%). \\
\hline
\end{tabular}

Table 2: Awareness of leading cause of Death in Austria among Austrians* 
Citation: Haidinger T, Sponder M, Stütz L, Demir D, Kaider A, et al. (2014) Influence of Migration Status and Gender on Awareness of Cardiovascular Risk Factors and Cardiovascular Health in a Group of Turkish Immigrants and Indigenous Austrians. J Gen Practice 2: 169. doi:10.4172/2329-9126.1000169

Page 4 of 8

\begin{tabular}{|l|l|l|l|l|}
\hline & \multicolumn{4}{|c|}{ Respondents } \\
\hline & \multicolumn{2}{|l|}{ Turkish Women } & \multicolumn{2}{l|}{ Turkish Men } \\
\hline Cause of Death & $\begin{array}{l}\text { For } \\
\text { Women in } \\
\text { Austria }\end{array}$ & $\begin{array}{l}\text { For Men in } \\
\text { Austria }\end{array}$ & $\begin{array}{l}\text { For } \\
\text { Women in } \\
\text { Austria }\end{array}$ & $\begin{array}{l}\text { For Men in } \\
\text { Austria }\end{array}$ \\
\hline $\begin{array}{l}\text { Cardiovascular } \\
\text { disease }\end{array}$ & $105(49.76)$ & $132(62.26)$ & $79(37.26)$ & $114(55.88)$ \\
\hline Cancer & $88(41.70)$ & $58(27.36)$ & $86(40.57)$ & $49(24.02)$ \\
\hline Accidents & $2(0.95)$ & $6(2.83)$ & $16(7.55)$ & $17(8.33)$ \\
\hline $\begin{array}{l}\text { Digestive tract } \\
\text { disease }\end{array}$ & $12(5.69)$ & $3(1.42)$ & $21(9.91)$ & $10(4.90)$ \\
\hline $\begin{array}{l}\text { Respiratory tract } \\
\text { disease }\end{array}$ & $4(1.90)$ & $13(6.13)$ & $10(4.74)$ & $14(6.86)$ \\
\hline *Data are given as number of respondents (\%). \\
\hline
\end{tabular}

Turkish women could identify CVD as the leading cause of death for women significantly more often than Turkish men $(p=0.009)$. Analysis of respondent's awareness of CVD as the leading cause of death for men in Austria showed no statistically significant difference between Turkish women and men $(\mathrm{p}=0.18)$.

Overall the level of knowledge of the Turkish participants' was low and greater effort has to be invested in educational programmes.

Knowledge of risk factors: It is one of the key objectives of this study to investigate the knowledge of CVD risk factors. The participants could choose between 8 answers corresponding to the eight main CVD risk factors; multiple answers were possible.

As shown in Table 4, all of the participants had a lack of knowledge of certain risk factors. Austrian men and women could identify significantly more often the following risk factors: obesity, hypertension, high cholesterol level and low physical activity $(\mathrm{p}<0.05)$.

The most remarkable finding was that diabetes could only be named by $28.3 \%$ of the Austrian women, $23.4 \%$ of the Turkish women, $26.8 \%$ of the Austrian men and $22.5 \%$ of the Turkish men. On average Austrian men and women knew four risk factors, Turkish women

three and Turkish men two.

Table 3: Awareness of leading cause of death for women and men in Austria among Turkish*

Respondents

\begin{tabular}{|l|l|l|l|l|l|l|}
\hline Risk factor & Austrian Women & Turkish Women & p-Value & Austrian Men & Turkish Men & p-Value \\
\hline Obesity & $452(80.0)$ & $190(59.19)$ & $<0.0001$ & $252(75.0)$ & $81(43.54)$ & $<0.0001$ \\
\hline Hypertension & $449(79.47)$ & $129(40.44)$ & $<0.0001$ & $269(80.06)$ & $68(36.36)$ & $<0.0001$ \\
\hline Smoking & $409(72.39)$ & $214(66.67)$ & 0.03 & $237(70.54)$ & $113(60.75)$ & 0.548 \\
\hline Little physical activity & $359(63.54)$ & $84(26.16)$ & $<0.0001$ & $173(51.5)$ & $31(16.58)$ & $<0.0001$ \\
\hline High cholesterol concentration & $337(59.75)$ & $150(46.73)$ & $<0.0001$ & $181(53.87)$ & $52(27.10)$ & $<0.0001$ \\
\hline Alcohol use & $199(35.22)$ & $115(35.83)$ & 0.79 & $130(38.69)$ & $69(36.90)$ & 0.419 \\
\hline Diabetes mellitus type 2 & $160(28.32)$ & $75(23.36)$ & 0.081 & $90(26.79)$ & $42(22.50)$ & 0.665 \\
\hline Positive family history & $77(13.63)$ & $57(17.81)$ & 0.38 & $28(8.33)$ & $15(8.06)$ & 0.243 \\
\hline *Data are given as number of respondents (\%). & & & & \\
\hline
\end{tabular}

Table 4: Respondents who correctly identified risk factors for cardiovascular disease.*

The analysis showed that the knowledge of risk factors was independent from the achieved level of education $(r=0.21)$. Austrian men and women who knew the term "CVD" were more likely to identify more risk factors $(\mathrm{p}=0.001)$ while familiarity with the term had no influence on the knowledge of the Turkish participants ( $\mathrm{p}=$ 0.42).

Austrian women and men who take more preventive action are more likely to identify more CVD risk factors $(p=0.001)$. This result was also found with the Turkish male cohort $(\mathrm{p}=0.006)$, while Turkish women could not name more CVD risk factors even if they had had preventive screening+ $(\mathrm{p}=0.39)$.

The number of correctly identified CVD risk factors, increased the probability to take part in prevention in the Austrian cohort (OR[odds ratio] $=1.18 ; 95 \% \mathrm{CI}, 1.08-1.28 ; \mathrm{P}=0.0002)$ but not in the Turkish cohort (OR[odds ratio] $=0.95 ; 95 \% \mathrm{CI}, 0.86-1.05 ; \mathrm{P}=0.32$ ).

\section{Prevention}

Reasons for prevention: The majority of Austrian men (66.3\%) and women $(70.5 \%)$ said they had taken preventive action in the last 12 months compared to $51.6 \%$ of Turkish women and $30.7 \%$ of Turkish men. In logistic regression models, positive factors associated with taking preventive action in the last twelve months were being a woman and being an Austrian ( $\mathrm{p}=0.0001)$. Table 5 shows the main reasons for prevention; each participant could tick several answers. Austrians were significantly more likely to regard feeling better, improving their health, being more successful, living longer, avoiding medication, feeling symptoms of CVD, because of better information through the media and doing it for the family as a motivation for prevention $(\mathrm{p}<0.05)$. 
Citation: Haidinger T, Sponder M, Stütz L, Demir D, Kaider A, et al. (2014) Influence of Migration Status and Gender on Awareness of Cardiovascular Risk Factors and Cardiovascular Health in a Group of Turkish Immigrants and Indigenous Austrians. J Gen Practice 2: 169. doi:10.4172/2329-9126.1000169

Page 5 of 8

\begin{tabular}{|l|l|l|l|l|l|l|}
\hline \multicolumn{9}{|c|}{ Respondents } \\
\hline & Austrian Women & Turkish Women & p-Value & Austrian Men & Turkish Men & p-Value \\
\hline Wanted to improve my health & $238(42.20)$ & $20(6.27)$ & $<0.0001$ & $153(45.54)$ & $32(20.92)$ & $<0.0001$ \\
\hline Wanted to feel better & $235(41.67)$ & $54(16.93)$ & $<0.0001$ & $123(36.61)$ & $9(5.88)$ & $<0.0001$ \\
\hline $\begin{array}{l}\text { Wanted to be more } \\
\text { successful }\end{array}$ & $98(17.38)$ & $38(11.88)$ & 0.0075 & $73(21.72)$ & $2(1.31)$ & $<0.0001$ \\
\hline Wanted to live longer & $107(18.97)$ & $19(5.96)$ & $<0.0001$ & $99(29.46)$ & $7(4.58)$ & $<0.0001$ \\
\hline Wanted to avoid medication & $87(15.43)$ & $25(7.84)$ & 0.0015 & $41(12.20)$ & $6(3.92)$ & 0.0061 \\
\hline Advice from physician & $47(8.33)$ & $35(10.94)$ & 0.75 & $48(14.29)$ & $3(1.96)$ & $<0.0001$ \\
\hline Felt symptoms of CVD & $27(4.79)$ & $11(2.73)$ & 0.17 & $37(11.01)$ & $7(3.13)$ & 0.0007 \\
\hline Better information via media & $47(8.33)$ & $7(3.44)$ & 0.0005 & $33(9.82)$ & $1(0.07)$ & $<0.0001$ \\
\hline Did it for my family & $67(11.88)$ & $17(5.33)$ & 0.0044 & $37(11.01)$ & $7(4.58)$ & 0.12 \\
\hline CVD in family member & $22(3.90)$ & $18(5.64)$ & 0.44 & $18(5.36)$ & $6(4.05)$ & 0.19 \\
\hline Advice from family menber & $24(4.26)$ & $20(6.27)$ & 0.59 & $13(3.87)$ & $2(1.30)$ \\
\hline CVD in friend & $17(3.01)$ & $2(0.06)$ & 0.113 & $21(14.19)$ & $0.63)$ \\
\hline *Data are given as number of respondents (\%). & & & & $<0.0001$ \\
\hline
\end{tabular}

Table 5: Reasons for taking action to lower risk of CVD.*

Preventive action taken: Each survey participant could specify the preventive actions taken to lower personal and family risk of heart disease over the preceding 12 months. Women were more likely to avoid more unhealthy food than men $(\mathrm{p}=0.0001)$. Austrian women quit smoking, added more physical activity, avoided more unhealthy food, lost weight and had annual check-ups significantly more often than Turkish women $(\mathrm{p}<0.05)$.

Except quitting smoking, which showed no significant difference between Turkish and Austrian men, Austrian men added more physical activity, avoided more unhealthy food, lost weight and had annual check-ups significantly more often.

Personalization of risk: Tables 6 and 7 shows the actual CVD risk and the relation between perceived CVD risk levels and defined risk status according to racial status. Women had a significantly lower risk than men $(p=0.005)$. Also the ethnicity had an influence on the actual risk. Turkish participants had a significantly higher risk than Austrians $(\mathrm{p}=0.035)$. Turkish women and men were at a significantly higher risk than Austrian women and men $(\mathrm{p}=0.0001)$. In addition to gender and ethnicity, also the menopausal status influenced the actual risk.

Postmenopausal women were at a higher risk of CVD significantly more often $(\mathrm{p}=0.0001)$ compared to peri- and premenopausal women $(\mathrm{p}=0.0001)$.

Self-assessment of CVD risk: More than half of the Austrian men and women, as well as the Turkish men seriously under estimated their actual risk, while Turkish women significantly more often over estimated their actual risk $(\mathrm{p}=0.0001)$ as shown in Table 7.

\section{Barriers to cardiovascular health}

Figure 1 outlines the main barriers to cardiovascular health in Austria for Turkish immigrants and Austrians.

\begin{tabular}{|l|l|l|l|l|}
\hline & \multicolumn{5}{|c|}{ Respondents } \\
\hline CVD Risk & Austrian Women & Turkish Women & Austrian Men & Turkish Men \\
\hline High Risk & $40(6.99)$ & $72(30.38)$ & $62(18.45)$ & $63(48.46)$ \\
\hline Intermediate Risk & $450(78.6)$ & $137(57.81)$ & $241(71.73)$ & $39(30.00)$ \\
\hline Low Risk & $82(14.34)$ & $28(11.81)$ & $33(9.82)$ & $28(21.54)$ \\
\hline $\begin{array}{l}* \\
\text { *Data are given as number of respondents (\%) } \\
\text { P=0.0001, Wilcoxon two-sample test }\end{array}$
\end{tabular}

Table 6: Actual CVD Risk.* 
Citation: Haidinger T, Sponder M, Stütz L, Demir D, Kaider A, et al. (2014) Influence of Migration Status and Gender on Awareness of Cardiovascular Risk Factors and Cardiovascular Health in a Group of Turkish Immigrants and Indigenous Austrians. J Gen Practice 2: 169. doi:10.4172/2329-9126.1000169

Page 6 of 8

\begin{tabular}{|l|l|l|l|l|}
\hline & \multicolumn{5}{|c|}{ Respondents } \\
\hline & Austrian Women & Turkish Women & Austrian Men & Turkish Men \\
\hline Underestimated Risk & $314(56.37)$ & $80(34.12)$ & $172(52.76)$ & $62(50.41)$ \\
\hline Correct Risk & $204(36.62)$ & $99(42.31)$ & $132(40.49)$ & $41(33.33)$ \\
\hline Overestimated Risk & $39(7.00)$ & $55(23.50)$ & $22(6.75)$ & $20(16.26)$ \\
\hline $\begin{array}{l}\text { *Data are given as number of respondents (\%) } \\
\text { P=0.0001, Kruskal-Wallis Test }\end{array}$ & & & \\
\hline
\end{tabular}

Table 7: Self-assessment of CVD risk.*

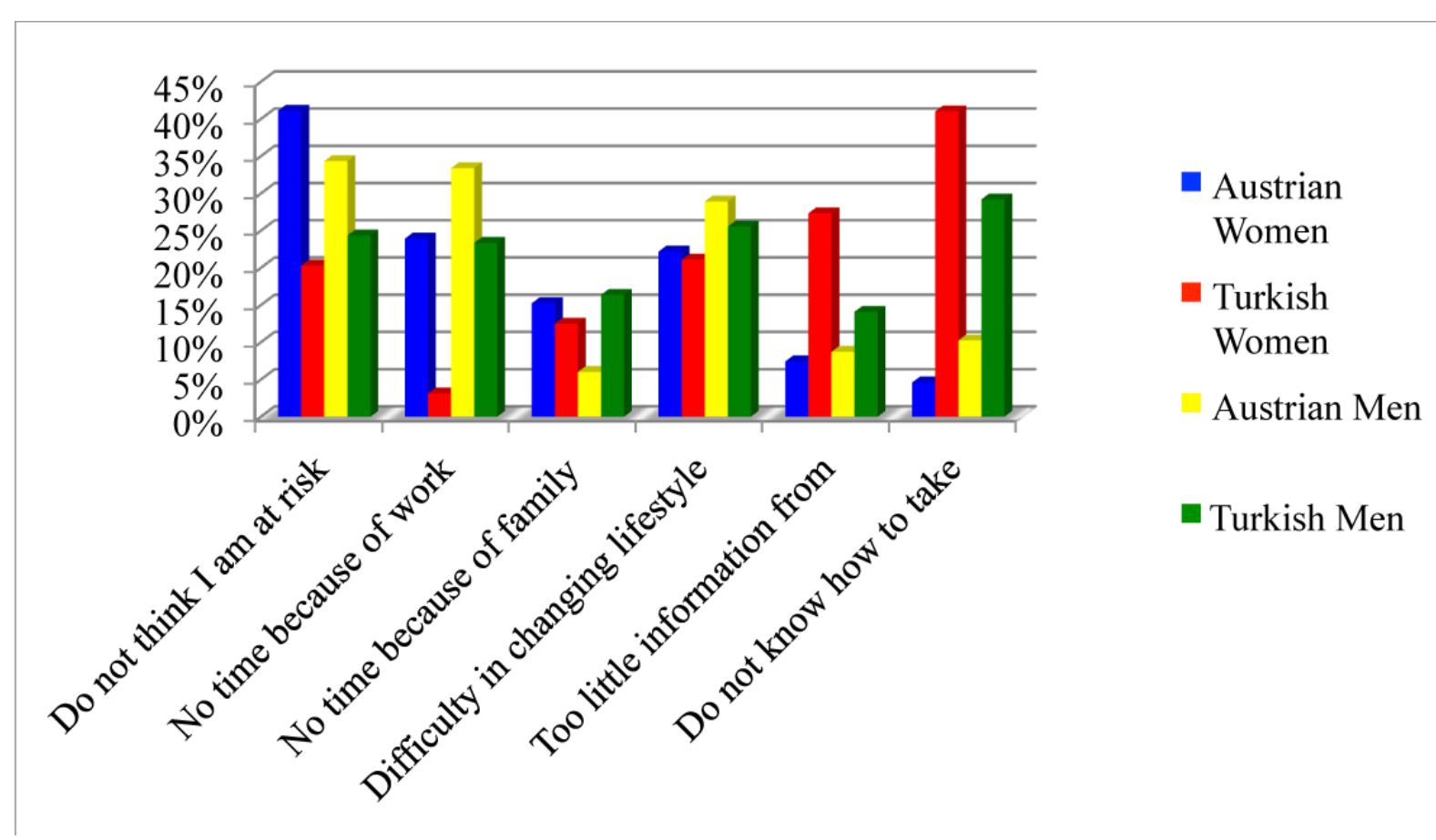

Figure 1: Barriers to Cardiovascular Health.

The disability to perceive the personal risk correctly is the main barrier to CVD health for Austrian men and women. By comparison, the main barrier for Turkish women and men is the lack of information from a physician and that they simply do not know how to take part in prevention.

As already shown, $85.7 \%$ of the Austrian women and $90.2 \%$ of the Austrian men have an actual high or intermediate risk and they are unable to correctly identify their risk.

By contrast, Turkish men and women can identify their actual risk much better but have a lack of information about taking preventive action. This has a large impact on further primary prevention programmes, as the efforts that have to be made differ between Austrians and Turkish immigrants.

Austrian men and women need an individual education about their actual CVD risk, while Turkish men and women urgently need more information about CVD and the avoidance of its risk factors.

\section{Discussion}

The present study was primarily designed to investigate the influence of gender and migration status on the level of CVD awareness and its risk factors, preventive action taken and barriers to cardiovascular health in a group of Austrians. We used two different questionnaires. The questionnaire for the Turkish migrants included 4 specific questions to evaluate the acculturation level. This was the only difference between the questionnaires.

There are several key findings from this study of randomly selected Turkish and Austrian adults in Austria.

First, there is a great social distinction especially between Turkish and Austrian women. $76.1 \%$ of the participating Turkish women only achieved a compulsory school education as the highest educational level, compared to $50 \%$ of Austrian women who finished secondary school or even had a university degree. This has consequences on the employment, $62 \%$ of the Turkish women are unemployed, and on 
Citation: Haidinger T, Sponder M, Stütz L, Demir D, Kaider A, et al. (2014) Influence of Migration Status and Gender on Awareness of Cardiovascular Risk Factors and Cardiovascular Health in a Group of Turkish Immigrants and Indigenous Austrians. J Gen Practice 2: 169. doi:10.4172/2329-9126.1000169

Page 7 of 8

income, 90\% earn less than $\$ 1050$ per month. Furthermore, there was a great gender gap, both for Austrian and Turkish women.

In Austria, less than $\$ 1050$ per month places the wage earner below the poverty line. By contrast, this difference concerning the educational level was not evident in men. $13 \%$ of the Turkish men achieved a university degree and with $86 \%$ full-time employed, the Turkish men could reach a much higher level than the Austrian men. However, the average age difference of 23 years between the Turkish and the Austrian men has to be taken into account, although the answers given were weighted. In addition, this increased social status of the Turkish men also had an influence on the acculturation level, which was significantly higher among the Turkish men compared to the Turkish women.

The socio-economic gap between Austrian and Turkish women as well as the gap between men and women in general is worrying as a low socio-economic status is correlated in women with an increase in CVD and developing a stroke in the future [14]. Second, the rate of awareness of heart disease as the leading cause of death among Austrian men and women is about $75 \%$, irrespective of gender. Anyway, a substantial gap in awareness remains for racial minorities, and Turkish immigrants still perceive a significantly greater threat for men than for women. These results are consistent with data from the US, where the risk for CVD for women was also highly underestimated [7]. Third, the level of awareness of CVD risk factors is alarmingly low, especially concerning diabetes and a positive family history regardless of gender and migration status.

This result matters especially for women because according to the Risk Assessment of the American Heart Association, women with diabetes are classified as at a high risk of developing CVD. In men, diabetes is associated with a twofold to threefold increase in heart disease and stroke [15].

Fourth, a surprising result was that the level of education achieved, did not have any influence on the knowledge of CVD risk factors and that the number of correctly identified risk factors had an impact on the preventive action of Austrians, but not of the Turkish men and women. The reasons for taking preventive action were nearly identical among Austrians and Turks. The role of the healthcare provider as a motivator for prevention was low for all participants, particularly for Turkish men.

In general, Turkish participants took part significantly less in prevention in the previous 12 months than Austrians. They significantly added more physical activity, avoided more unhealthy food and had regular contact to a healthcare provider compared to the Turkish men and women. Furthermore, the impact of preventive measures taken for others was significantly higher among Austrian men and women and therefore lead to an improved health not only for themselves, but also for partners and children.

Future preventive programmes should not only educate adults to a more healthy heart lifestyle, but also tackle the problem of assessing the Austrian healthcare system, which obviously exists for Turkish immigrants.

Fifth, Turkish immigrants have a significantly higher risk of CVD than Austrians without immigration background. The great number of high-risk Turkish participants can partly be explained by the high rate of diabetics among the Turkish immigrants. Sixth, approximately half of the Austrian men and women seriously underestimated their actual CVD risk based on national standards, which was at the same time the most commonly reported barrier to cardiovascular health. This finding corresponds to data from the US, where one-third of women underestimated their personal risk [7].

By contrast, a majority of Turkish women correctly identified their personal CVD risk. For them, the main barrier was the lack of knowledge about how to access prevention and too little information from the healthcare provider.

Turkish men even overestimated their actual CVD risk and also stated that they simply do not know how to take preventive measures.

Thus, the barriers to cardiovascular health differ enormously between racial/ethnic groups which will lead to different approaches in future cardiovascular preventive programmes.

Turkish immigrants urgently need more information about CVD and the preventive measures that can be taken, while Austrians have to be educated about their individual risk and its consequences.

Our study has several important limitations that should be taken into consideration when the findings are interpreted and extrapolated.

First, the findings of the present study cannot be regarded as valid for the whole Austrian population, as it is not representative for Austria's population. The questionnaire was handed out randomly to patients in a urology department, a gynaecology practice, a general practitioner's practice, to employees in three large companies, to visitors of cultural centres and mosques in Vienna. Therefore, this pilot study is the basis for acquiring a large representative data sample from all over Austria. Second, our data are based on self-report therefore the health information especially concerning the risk factors may be inaccurate.

Third, the data was collected using a questionnaire. The classification of the participants as at low, intermediate or high risk was performed on the basis of self-reported risk factors.

Fourth, this was a cross-sectional design; cause and effect cannot be determined. Fourth, only Turkish immigrants were surveyed, thus the results may not be applicable to adults from different ethnic and cultural backgrounds.

\section{Conclusion}

The results of this present study show that there are large socioeconomic differences between indigenous Austrians and Turkish immigrants. These differences lead to a higher risk for CVD.

In addition, there is a lack of knowledge of CVD risk factors among all participants, especially regarding diabetes.

Future preventive efforts should not only be gender-sensitive, as Austrian women in particular have to be informed about their actual CVD risk, but should also take ethnic/racial disparities into account. The barriers to cardiovascular health especially differ enormously between the ethnic/racial groups. The inability to correctly identify the personal risk affects mainly indigenous Austrians while Turkish immigrants struggle with the assessment of the healthcare system in Austria and the lack of information provided by official health authorities.

\section{Competing Interests}

This study was supported by Femtech FTI, a public grant from the ministry of innovation and technology of Austria. The authors have 
Citation: Haidinger T, Sponder M, Stütz L, Demir D, Kaider A, et al. (2014) Influence of Migration Status and Gender on Awareness of Cardiovascular Risk Factors and Cardiovascular Health in a Group of Turkish Immigrants and Indigenous Austrians. J Gen Practice 2: 169. doi:10.4172/2329-9126.1000169

Page 8 of 8

indicated that they have no other conflicts of interest regarding the contents of this article.

\section{Authors Contributions}

Dr. Haidinger contributed to the literature search, figure creation, study design, data collection, data interpretation, and writing.

Dr. Sponder contributed to the literature search and study design.

Dr Stütz contributed to the literature research, data collection, and data interpretation.

Dr Demir contributed to the literature research, data collection, and data interpretation.

Dr Kaider contributed to the data interpretation.

Dr Strametz-Juranek contributed to the literature search, study design, data interpretation, and writing.

\section{Acknowledgements}

We thank Lingua World, a well-respected translation agency, for review and correction of the manuscript. We also want to thank Martin Zweimueller who contributed to the design of the study as well as the data collection.

\section{References}

1. http://www.statistik.at/web_de/statistiken/gesundheit/todesursachen/ index.html

2. http://www.integration.at/fileadmin/Staatssekretariat/4-Download/ Integrationsbericht_2012/migration_integration_2012_72dpi.pdf

3. Poisson J, Six M, Morin C, Fardet L (2013) [Glucocorticoid therapy: what is the information sought by patients? Traffic analysis of the website cortisone-info.fr]. Rev Med Interne 34: 255-257.

4. Bader A, Musshauser D, Sahin F, Bezirkan H, Hochleitner M (2006) The Mosque Campaign: a cardiovascular prevention program for female Turkish immigrants. Wien Klin Wochenschr 118: 217-223.
5. Onat A (2002) On the coronary heart disease mortality in Turkey. Atherosclerosis 163: 203-204.

6. Langellier BA, Garza JR, Glik D, Prelip ML, Brookmeyer R, et al. (2012) Immigration disparities in cardiovascular disease risk factor awareness. J Immigr Minor Health 14: 918-925.

7. Mosca L, Mochari H, Christian A, Berra K, Taubert K, et al. (2006) National study of women's awareness, preventive action, and barriers to cardiovascular health. Circulation 113: 525-534.

8. Shaw LJ, Bairey Merz CN, Pepine CJ, Reis SE, et al. (2006) WISE Investigators. Insights from the NHLBI-sponsored Women's Ischemia Syndrome Evaluation (WISE) Study. Part I: gender differences in traditional and novel risk factors, symptom evaluation, and genderoptimized diagnostic strategies. J Am Coll Cardiol. 47: S4 -S20.

9. Ockene IS, Miller NH (1997) Cigarette smoking, cardiovascular disease, and stroke: a statement for healthcare professionals from the American Heart Association. American Heart Association Task Force on Risk Reduction. Circulation 96: 3243-3247.

10. Poirier P, Giles TD, Bray GA, Hong Y, Stern JS, et al. (2006) Obesity and cardiovascular disease: pathophysiology, evaluation, and effect of weight loss: an update of the 1997 American Heart Association Scientific Statement on Obesity and Heart Disease from the Obesity Committee of the Council on Nutrition, Physical Activity, and Metabolism. Circulation 113: 898-918.

11. Hu FB, Manson JE, Stampfer MJ, Colditz G, Liu S, et al. (2001) Diet, lifestyle, and the risk of type 2 diabetes mellitus in women. N Engl J Med 345: 790-797.

12. Mosca L (2004) Cardiology patient page. Heart disease prevention in women. American Heart Association. Circulation 109: e158-160.

13. Ellison J, Jandorf L, Duhamel K (2011) Assessment of the Short Acculturation Scale for Hispanics (SASH) among low-income, immigrant Hispanics. J Cancer Educ 26: 478-483.

14. National Cholesterol Education Program (NCEP) Expert Panel on Detection, Evaluation, and Treatment of High Blood Cholesterol in Adults (Adult Treatment Panel III) (2002) Third report of the National Cholesterol Education Program (NCEP) Expert Panel on Detection, Evaluation, and Treatment of High Blood Cholesterol in Adults (Adult Treatment Panel III): final report. Circulation. 106: 3143-3421.

15. Goldschmid MG, Barrett-Connor E, Edelstein SL, Wingard DL, Cohn BA, et al. (1994) Dyslipidemia and ischemic heart disease mortality among men and women with diabetes. Circulation 89: 991-997. 